\title{
An Economy of European Identity: What Culture?
}

\author{
WILLIAM ANSELMI \& LISE HOGAN \\ I. THE EUROPE WE HAVE ALWAYS KNOWN
}

Two recent Chechen-Russian wars have taken a disastrous toll on the In order to contextualize this work, the specifics of the discourse undertaken must be presented. The point of view offered with regards to the formation of the European Union as a dynamic process is from a humanistic perspective. What will color the analysis is the concept of ethics, and this will be placed within the cultural structure of the EU as an ongoing, multicultural reality. In doing so we would also like to posit what the notions of agora and Heimat might suggest in terms of the problematic that arises with regards to the vision of the European Union. Briefly, then, in positioning agora as any communicative and informative space (concrete or virtual) where citizens meet to discuss the politics of everyday life, and by recuperating the term Heimat as that indicating the bounding relationship between people of the same family, of the same group, we intend to use the terms to show the tension that is at stake for the various forces shaping the EU while trying to arrive at a common platform.

Yet, after the preliminary framing of our discourse, the concrete reality of the European Union must be brought to the fore in so far as recent events have shaped that reality. After France and Holland's refusal of the new European constitution in the late spring of 2005, the economic vision of an integrated Europe has defaulted. At stake was more than how to manage economically a 25 -state model. What the 
responses to the various referenda have shown is evidently a lack on the part of the three European bodies (Parliament, Commission and Council) to address a cultural policy as an integrative model. Originally, the plan of a united Europe was, first and foremost, to avoid other bloodbaths as envisioned by the likes of Altiero Spinelli, and the development that has taken place has been quite successful on that front. However, the integrating dynamic has been left mainly to the economic process, and as such, it has been called into question by the negative referenda responses. Perhaps, though late at this stage of the process, what must be addressed is the cultural area where questions of identity are crisscrossed by reality-shaping technologies and processes of globalization. A possible starting point, for us, is the question of ethics as a framing mechanism for the European Union.

If we can agree that ethics, as a conceptual framework, means a set of shared values on the part of the citizens as individuals of the EU, the first problem is to define precisely what constitutes this set of shared values. Ethics, in its construction, has been formed by extrapolating and applying values from a common culture sustained by a common language. The traditional relationship between culture and language is one that is inextricably tied to an historical formation of a particular anthropological space as a lived reality. Europe as a geo-political entity has formulated its history on a common ethic based on a language, Latin, and on the "tolerance" of one religious culture, Christianity, that still lingers in the complex definition of what it means today to be European. By stating this, what is being addressed is not an indication of what could be interpreted to be the recuperation of a tradition. What is being discussed is the genealogy of a "European" formation and the necessary notion that it is only by being aware of historical trajectories that the future might be less a hazard and more an encompassing and elastic social framework. In the past, for a specific period, what came to be Europe sustained the inclusion of Heimat within the more generalized space of an extended agora, given the precise borders of a constitutive religious and political culture. Of course, such a process was constituted by the specific dynamics of inclusion/exclusion of the designated Other (women, members of other faiths, invaders, etc) by part of the power structures of the period.

The necessity of addressing at the start the sense of history that permeates European reality is made even more pressing by the fact that a general sense of history, in our present condition in the Western world, is being undermined if not necessarily subtracted from the experience of 
everyday life by political and economic forces, the result of which is to erase history from the individual's experience of life. This is so since living in an 'eternal present' is conducive to a system that necessitates social control as a modus vivendi. An individual, a subject, a citizen whose sense of history is negated is an easily manipulated being, a dupe waiting to be empowered by entertainment. That is, if we can refer to popular culture with the Beatles, we are all content being part of a process, which is supposed to make of us "fools on a hill." Yet, such a cultural reference from the English pop world of the sixties is not gratuitous since it serves the simple purpose of indicating, once again, the general problem faced in the construction of Europe. Given that Latin and Christianity are not references which are chartered as obligatory values in the European constitution, what language and therefore what culture is to be the foundation for a European ethics? Can more than one co-exist and still give form to a shared ethics? By our reference to the Beatles, we have by sleight of hand introduced at the periphery of the discourse the question of technology and of the multimediatic space we all have come to inhabit in the present world. It is quite obvious to anyone who deals in the process of communication/information, for example, that the predominant form of communication and information is the English language and that the World Wide Web is shaped by it; downloading the song "The Fool on the Hill," one is instantaneously part of a specific community.

A philosophy of ethics has evolved over the course of the centuries in many ways. One could go from grounding the discourse in a closed, social Aristotelian reality to one based on a religious enclosure of the medieval period, to one based on an economic discourse as was the case for Adam Smith and Marx, to the present fragmentation of the subject given the various paradigm shifts - finally, models of conduct - that have occurred in the late nineteenth and early twentieth centuries. Generally, then, one can talk about ethics as an historical process that develops and is transformed by the evolution of societal contexts. Parallel to this, undoubtedly, is the discourse of progress, which is a general attribute of modernity and one that, epistemologically, still informs us. Ethics, as we have already stated, needed a shared culture, a shared language, not only a shared sense of history and/or development.

The question, then, is simply this: is it possible to frame the EU around a multicultural ethics? That is, can a set of visibly behavioural values, how one acts in society (by saying this we are being reductive on purpose, in a Wittgensteinian sense), emerge from different languages 
and cultures, from a multicultural and multilingual space as the EU is now? In addition, subsequently, will the process inevitably lead, once again, to a dominant language and to a dominant culture, as has been the case?

The Western world, as it has come to define itself, is at present under the strain of a dominant economic and cultural discourse that inescapably engages the rest of the world. Such a process has been given many names from Empire to Manifest Destiny, all of which seem to treat the process as an independent state of affairs, and not as a direct consequence of European expansionism. It is impossible to escape from such considerations the moment one is part of the information process, of the multimediatic circuit that shapes our lifeworld. The war in Iraq as a fallout also produced a tension that still resonates within the EU, splitting and polarizing various members along the way. Not only has this occurred along political and economical lines, but also, and most importantly for us, along cultural lines. Certain cultural operators have talked about a great philosophical divide occurring between Europe and the USA, one Kantian and the other Hobbesian. Although it is not our intention to explore here at great length this divide, we contend that it is a false dialectic since polarization always brings into play absolutes that resist any type of synthesis. Yet, the vision of a world based on the struggle between nature and society (Hobbes) against one based on the problem between ethics and history (Kant) must be considered since it assumes in its discourse an epistemological construct stuck in time, with all the contradictions that permeate such a position. Along these lines then, a dominant economic, cultural and linguistic paradigm is already at work in the world, shaping - as it manifests itself - the limits of any other economic, cultural and linguistic model-in-the-making as is the case for the EU. Given such a forceful constraint, the aspect of multilingual and multicultural nation-states (we are purposely pluralizing the second part of this conceptual framework) must, by necessity, become a utopic discourse based on historical development. What is shared, and still materially and visibly so, in the EU is a common culture based on a humanistic narrative. In the end, if we are to listen to Milan Kundera in his latest book Le rideau (The Curtain), Europe became Europe because its art became its history. That is, certain writers and artists, transcending the confines of national literatures, became the common wealth of a Europe-in-becoming. Therefore, in order to answer the question of the possibility of framing the EU around a multicultural ethics, one possible starting point for an answer is to trace the genealogy 
of a European culture (which does not necessarily translate into forced Eurocentrism). In doing so, in the act of engaging oneself with a common, humanistic culture and its genealogy, one finds the possibility to ground each state into a federalist nation with an ethics, a shared set of values that emerge from a shared narrative. After all, if the act of reading has taught us anything, it is that a society comes together as a narrative of which ethics is the grammar. The developing process that is being presented is ground in history, but does not turn to stop and look back like some angel of history à la Benjamin, since it comes to encompass in its formative gaze the developing horizon. In such a fashion, the question of one language-one culture is extended by a culture with different, shared languages. Ethics is then formed as the Heimat that consolidates itself and extends itself through the common agora in a dynamic process.

By having posited this, we realize that the position presented could be seen as weak, easily deconstructable in contrast to the dominant cultural paradigm of postmodernism. Postmodernism has quite successfully masked the ideological intent that governs it, by deconstructing History from a set of Great Stories (given as the ideological foundations that constituted Fascism, Nazism, Communism) to the individual stories of everyday life, without calling into question its own origins and its own locus of power. In other words, while destabilizing the precarious balance of modern thought, postmodernism has managed to hide its own ideological construct and the discourse of power associated to it. This manipulative discursive practice would have made Wittgenstein turn to Nietzsche's hammer were it not that the philosophical escamotage operated within postmodernism should be seen as the extent to which the multimediatic world operates. After all, isn't the web a beautiful arena of many extraordinarily different, small stories all interlocking in a hyper-anarchic process, a case where the agora and Heimat merge one into the other, and cancel each other out in re-creating the free world of Francis Fukuyama's fame?

The ironic allusion we have made to techné as not just another problem in the formation of a common ethics for the EU is now becoming increasingly evident since it permeates the lifeworld as a constitutive and manipulative element. The immediate danger is the dematerialization of the experience of life, since the application of technology, as it expands into every detail of our individual lives, filters out the agora and inescapably reduces the grounds of Heimat. Increasingly technology, which we still regard as the proved proof of progress, is associated with the way we communicate. The portable 
phone is such an index: anyone who travels from A to B can catch the ongoing comedy of people on the street who gesticulate more or less depending on the latitude -, and who are seemingly in a state of constant chatter with themselves. The translation for such a state of affairs is quite banal: the more we are connected, the less we interact. The famous European piazza has not been displaced by the super-sized malls of American fame, but is on its way to redundancy as our paths cross without notice, since we are always elsewhere within our system of communication. Such a small example, when entwined with such things as the web, being wired, surveillance, virtual reality, etc posits a radically different type of society. We suspect that even the common background we share is being altered imperceptibly but inevitably as we speak. Speed is the ultimate goal which can never be achieved; we're already bored with 'yesterday.' The speed by which we move towards any possible futures undermines constantly the history of the formation of an ethics of the EU, as the genealogy which should re-constitute it is still ground in the written word while we are overtaken by the immaterial space of images. Such a process, techné coupled with speed, is directly tied to the present economic conditions: unbridled capitalism. The EU, when first born as the exchange market of basic material for the founding nations (steel and coal), used those economic ties as the grounding base upon which a united Europe would be formed. The utopic discourse resorted to the pragmatics of a common, constitutive language, the economy, as its framework. In a way, notwithstanding the process of an integration of intents from the economic to the cultural, the auspicated development and transformation has lagged and inevitably so. So that asking today about a grounding ethics for the EU is not just how to face a difficult challenge, but the necessary revisionism in the past of the present, if we can speak through this paradox. The difficulty of a multilingual, multicultural reality brought into a cohesive system is less of a problem than how to deal with the way individuals are being informed by technology. The palpable, unmediated risk is to arrive at a culturally and linguistically unified agora, having as its inhabitants virtual beings whose Heimat could be on the dark side of the moon for all that matters.

Such a risk, however, is at present being pushed aside by more concrete and political considerations that have little to do with a federalist Europe and more to do with its relevance and threat in world political agendas. After all, if we were to consider the latest fears of expansion of the EU, the role that Turkey plays in such a context is 
seemingly without a real solution. Pushing it into a time frame of ten or so years is not really a solution but part of the problem. For, what is Turkey if not the destabilizing agent that can be used by the US/UK agenda to keep the EU underdeveloped as a (multi)cultural reality? Notwithstanding Cyprus's concerns or various political moves, such as certain EU members making space for Slovenia in exchange for considering Turkey a candidate or appealing to a Christian sense of history, is it not the case that the process of inclusion has failed its prerogatives? After all, and we insist on this point, was it not the case that the EU was foreseen as an idealized reality and only then a cultural and economic community? Perhaps as the confusion is great under the sky of Europe, this is an excellent moment to reconsider the whole EU project. To re-group, basically. And to re-introduce a concept which might be quite useful right now. The concept of a two-speed Europe, the re-constitution of two areas of participation: one strictly economic, as the present structure would indicate, and the other, and we end with the other as a conceptual framework but, of course, constituted by that small number of states which, originally, had foreseen not just the economic but also the cultural integration as the constitutive procedure for an original experiment of social cohesion.

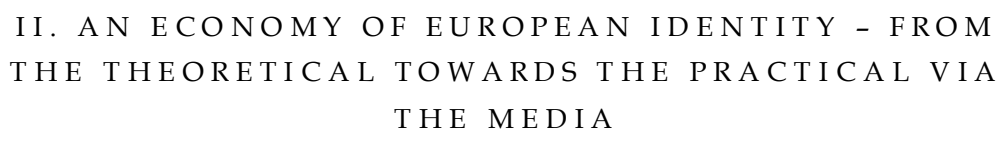

Towards the Differentiation of Discursive Practice, The Case for 'Reform'

Recent events seem to suggest that the EU experiment - since it is a workin-progress of sorts - has yet to culturally ground itself on a concrete structural framework. This is something we have alluded to, however ironically, in the first part of our work.

This 'constitutive fragility,' which is both the strength and weakness inherent in the 'becoming complex' of the unification of varied histories/cultures (continuously re-integrated in terms of a 'greater' Europe), leaves the experiment open to a number of critical interventions, interventions characterized by a seemingly beneficial set of factors which are more in keeping with stalling the process, hijacking it or derailing it (the media reformist ideology) - as we shall try to prove -, than to filtering the contents of the process in order to make it sustainable as an ideal and a practice (the reformist ideology tout court). What is at 
risk in the present world-system is the notion itself of cultural, social, and political systems capable of contrasting and offering livable alternatives to the world order we have come to inherit.

Necessity dictates the need to come to terms with the use of the concept of 'reform.' Such a term has invariably assumed different connotative aspects throughout the course of the last few decades, especially if we take the symbolic time period of the fall of the Berlin Wall as a starting point. Reform is not only a potentially charged label but also a distinct - or, the way it has come into distinction - modus operandi: a process by which the Enlightenment's notion of progress has had to be reformulated in terms of subtle semantic shifts that have come to include in its repertoire (of the term 'reform') contradictory political cognitive spaces, spaces that can entertain, with the blink of an eye, both the theory of 'intelligent design' and 'stem cell research,' for example.

The reader will not fail to see in the use of such references and metaphors a propensity towards 'cultural framing devices' common to a dominating space of identity presently en vogue. Yet, such a bias cannot escape the zeitgeist, to use another term fallen in practical disuse given the velocity of, or instantaneous appearance of, culturally bounding newscasts (from podcasts, to blogs, to 24-hour TV news channels). In keeping with the groundwork established by the Italian cultural critic Pier Paolo Pasolini, the attempt at a critical analysis, however controcorrente (counter-current), is to delineate a process by which the very notion of 'reform' can be shown to have assumed a plus-valence of meanings. To navigate such a process, then, is to characteristically engage in semantic choices that must be continuously spelled out, contextualized, if one is to arrive at any sustainable assessment of the present conditions of the EU project. Following this, the necessity of distinguishing at least between two invariably contradictory tenants becomes apparent in the formulation of a) the media reformist ideology and b) the reformist ideology tout court. The two, though they derive their discursive framing from the same basic conceptual background, can be said to be part of a false 'family-relation' if we were to invoke Wittgenstein's work on such relationships of meaning. In fact, because of the techno-cultural developments present (especially since the later part of the twentieth century), the divergence that takes place posits interesting developments as far as cognitive frameworks are concerned. Basically, the media reformist ideology (technologically grounded), uses as a legitimizing agent the reformist ideology tout court. It does so in order to frame, in a regressive form, particular social events in terms of 
the dominating cultural/political apparatus while presenting the façade of a 'reformist' vision. In other words, a progressive, pro-active discourse is presented as a vehicle for a substantially regressive (but, not conservative) narrative.

\section{A controversy of cartoons}

The period starting with the publication on the 30th of September 2005 by the Jyllands-Posten, a well-known Danish newspaper, of twelve cartoons under the rubric 'The Faces of Mohamed' sets the stage for our critical analysis by a brief historical background. What briefly follows are some of the highlights of the process.

On the 12th of October 2005, the editor-in-chief of the newspaper receives death-threats while about a thousand Muslims protest in Copenhagen. On the 20th of October 2005, eleven ambassadors from Muslim countries, while in Copenhagen, protest in front of the office of Liberal Prime Minister Anders Fogh Rasmussen, who refuses to see them. On the 5th of January 2006, an agreement is reached between Denmark and the General Secretary of the Arab League, Amr Moussa, for the distribution in Arab countries of a letter from Rasmussen who, while defending freedom of expression, condemns any action that demonizes groups because of creed and ethnic belonging. On the 10th of January 2006, the Norwegian newspaper Magazinet again publishes the twelve cartoons. Two days later, the editor-in-chief claims to have received death-threats.

The controversy that grew out of this state of affairs, as other newspapers both in Europe and North America published some or all of the cartoons, eventually led to violent repercussions across the world, especially in certain Muslim countries. About 139 people have died in such different locations as Nigeria, Libya, Pakistan and Afghanistan.

The original intent, as expressed by Flemming Rose, the JyllandsPosten's culture editor in his September 30th, 2005, article "Muhammeds ansigt" ("The Face of Muhammad"), was that of dealing with selfcensorship in the Western world at large when dealing with texts that involved representation of the Muslim faith and the understanding of contemporary democracy and freedom of speech:

The modern, secular society is rejected by some Muslims. They demand a special position, insisting on special consideration of their own religious feelings. It is incompatible with contemporary democracy and freedom of speech, where you must be ready to put up with insults, mockery and ridicule. It is certainly not always attractive and nice to look at, and it does not mean that religious feelings should be made fun of at any price, but that is of minor importance in the 
present context.... we are on our way to a slippery slope where no one can tell how the self-censorship will end. That is why Morgenavisen Jyllands-Posten has invited members of the Danish editorial cartoonists union to draw Muhammad as they see him.[1]

If we take the statement at face value (without forgetting that the text considered is a translation into English), the reader will not fail to notice certain presuppositions that mark the ideological position of the writer. Democracy - albeit in this special case - is reduced to "you must be ready to put up with insults, mockery and ridicule," something that is constitutive of "modern, secular society," which is "rejected by some Muslims" who keep "insisting on special consideration of their own religious feelings." Perhaps the writer was thinking about the recent past, and such things as the Inquisition and the periodic witch-hunts that have marked for several centuries the cultural developments of the Western world, finally equating the two histories (the Western, the Muslim) without making proper religious connections (the Inquisition and the witch-hunts developed from the Christian religion's view of things), as if to say that present democratic systems have rejected that particular religious credo in favor of a fully secularist society. A dubious tenant at best, since it is quite evident that Christianity still plays quite an important role, culturally, politically, in certain countries in Europe and North America. Or, it is also possible that the very same writer had a selective case of amnesia since for the Islamic faith any representations of their prophet are seen as blasphemous. In this case, respect of religious differences - which is integral to democratic participation - is conveniently forgotten.

In a way then, the position taken in the article expresses a refusal of religious sensibilities prescribed to a particular group, while omitting, or hiding, the fact that the claim of a secularist position is only to be applied to another group which, nevertheless, develops from a different religious experience. Not only that, but the reduction of democratic practices to the level of putting up with "insults, mockery and ridicule" negates the continuous negotiations at a social and political level that marks such cultural events. It could be argued that if Christians in general were asked to accept at large, as part of democratic participation, the genderization of their God as a female being, protests would have erupted as well. But, of course, what is being invoked is a process of cultural relativity, which for some Christian figureheads is equally reprehensible. 
Finally, the position assumes a polarized perspective which negates, ceremoniously and humorlessly, precisely the democratic process envisioned. On one side, some Muslims who fundamentally reject democracy because of their religion; on the other, the "democratic clowns" enjoying their freedom of speech quite seriously. Were it not for the numerous deaths that occurred because of the controversy, one could dismiss the above article as another amongst a host of examples of "nonnegotiable ideological perspectives" that mar the present fluid and chaotic formulations that accompany the development of the EU project. However, another article by the same author, this time published in the Washington Post, on February 19th, 2006, gives rise to other speculations that emanate from the first article:

The cartoonists treated Islam the same way they treat Christianity, Buddhism, Hinduism and other religions. And by treating Muslims in Denmark as equals they made a point: We are integrating you into the Danish tradition of satire because you are part of our society, not strangers. The cartoons are including, rather than excluding, Muslims.[2]

This time, humor (satire) is used to underscore the idea of "integration" within the greater Danish society of the special category: Muslims. Gone is the qualifier "some" from the previous article; now it is the whole of Muslim society which must accept that its religion can be made fun of, as a sign of integration into the larger Danish society (which by this point in time has assumed the connotation of the whole of the Western world, given the context of the second article: The Washington Post).

Of course, questions arise as to who/what is to be "integrated," the very process of integration (does it stand for "assimilation"?), and the use of satire as a litmus test for democratic participation. But, most important is the omission of the greater context that surrounds the process delineated above - since the controversy has not been magically erased from having occurred. At no time has the on-going war in Afghanistan and Iraq ever been presented as a cultural constituent of the 'religious sensibilities' displayed by what were initially 'some' Muslims in Denmark. This grave and tragic omission is for us the proper cultural test of pseudo-democratic statements (reformist, progressive, occurring within the mediascape - from newspapers to TV news to internet blogs, etc) that are in reality regressive propositions of the state of things. As such it is not conservative, since such a position would invariably define itself accordingly in the democratic negotiation process. The media reformist ideology bypasses by its very process any type of negotiation, since it espouses a progressive view while operating 
as a regressive social construct. By doing so, it renders obsolete and undermines - at a practical level - the very political categories that are still embedded in Western societies as constitutive of democratic participation and responsibilities, that is the very notion of progress.

Another humorless world is possible

Is the process delineated above, the media reformist ideology construct, inescapable as we become more and more technologically interconnected?

Primarily, we believe that such a process is part of an epochal shift which is still taking place with the Western world as a point of departure. The shift is from a society that derives and responds to its information from the written word to one elaborated along the lines of techno-progress: information as sets of moving images. Given these premises, the information process has been moving from the reflective (the written word) to the emotive (the moving image). This movement from the reflective to the emotive is best illustrated by the media reformist ideology since it is here where the "image-laden information process" triumphs, overriding any attempt at critical reflective processes. As we have implied in our brief illustration above, any critical attempt is vanquished by the sheer force of the image-impact that frames discursive practices. The various television reports that have shown the reaction in particular Muslim countries to the cartoon controversy have been able to polarize the average viewer in the now typical world of "culture wars" so aptly blueprinted by Samuel Huntington back in the mid-nineties. The very same script has legitimized, under the surface of things, the state of "continuous war" as invoked primarily by various regressive groups (religious and secularist) in the US, and which has found in Iraq a modus operandi.

Invariably, any critical assessment is by its very nature a political perspective, notwithstanding the fact that the epochal shift in progress requires the de-politicization of the lifeworld, and with it, all political categories as we move towards a neutral but paradoxical framework of social references aptly encasing the individual subject within an emotive pseudo-participatory world. So, as we attempt to maintain the critical tools derived from the political sphere tout court, the encounter(s) between the mediated social groups that are still constitutive of the social arena in the Western world still see the practical engagement that derives from the practice of social criticism. To illustrate this, we must 
return to specific critical positions which nevertheless circulated, however limitedly, within the process illustrated above.

Annamaria Rivera, in her article "Vignette o stereotipi? Le radici di un caso" ("Cartoons or Stereotypes? The Roots of a Controversy"), which appeared in the Italian left-leaning newspaper Liberazione on the 18th of March, 2006, presents an uncontextualized critical assessment of what had occurred. First of all, the ideological positioning of the Danish newspaper (which was never part of the discursive Western media framework) was reported as being the spokespiece for an antiimmigration and anti-Muslim political party (socio-political context) in Denmark. But her criticism does not fulfill the partial lens of political opposites; in fact in her analysis she presents the larger context:

Isolare la vicenda dalla temperie del dopo 11 settembre per iscriverla nella categoria, concepita come astratta e immutabile, della libertà d'espressione è un'operazione alquanto sospetta, tanto più se i difensori del principio assoluto della libertà di "satira" sono gli stessi che mai hanno nominato, a proposito di questa vicenda, la parola razzismo.

(To isolate what has happened from the political climate of the 11th of September in order to enter it into the category, conceived as abstract and unchanging, of freedom of expression is a suspect operation, especially so if the defenders of the absolute principle of the freedom of 'satire' are the same who have never mentioned throughout this the word racism.)

The analysis is to the point: Muslims have been represented through the racist stereotype only as potential terrorists and the Islamic religion as pure violence - notwithstanding the present conditions Muslims live under in such places as Afghanistan and Iraq. As well, the anti-Muslim discourse resembles another discourse, a sadly infamous one: the antiSemitic discourse. As we wrote in an article which appeared in March, 2006 for Trentagiorni with reference to her article:

Nella sua analisi, la giornalista è riuscita ad indicare criticamente non solo come sia indispensabile una lettura attenta del testo e del contesto, ma anche la necessità di evidenziare nettamente i problemi ed i risultati, quella responsabilità - come scordarsi dei morti causati dalle vignette? - negata dalla voluta ignoranza del rapporto già indicato.

(In her analysis the journalist has been able to critically show not only the necessity of a reading which incorporates text and context, but also the need to neatly foreground the problems and the results, the responsibility - how can one forget the deaths that have come about because of the cartoons - denied by the intentional ignorance of the relationship shown above). 
In this context, then Italian Minister for Institutional Reforms Roberto Calderoli's decision on the 15th of February 2006 to wear a t-shirt depicting one of the infamous cartoons and to publicly display it on Italian national television was an act of provocation with a precise result: eleven people dead in Libya, when about 1,000 people violently protested against the Italian consulate in Bengasi and the police had to intervene. Rather than being a question of freedom of speech, as the repeated display of such cartoons would indicate, the whole process can be seen as part of an intentional strategy to further polarize the Western world into two opposite cultural and religious camps, with the religious space absorbing the cultural frames. Canada also had a say in this: from the philosophy professor in Halifax who displayed the cartoons on his office door to the right-wing Western Standard's decision to republish the cartoons on February 13, 2006. Interestingly enough, Conservative Defence Minister Gordon O'Connor intervened by criticizing the decision to republish the cartoons since he thought this could endanger the lives of Canadian soldiers in Afghanistan. Yet, no connection was made in the various media reports that analyzed the arrest of the Toronto-17 (an abbreviation for the seventeen men and youngsters of Islamic creed arrested on several terrorist charges in June 2006).

What is important at this stage is to delineate the process of polarization, and the strategy behind the cartoons controversy. The media reformist ideology suggests a practical reading if we are to consider the controversy as a cultural trap with political consequences. After the EU failed to pass the referenda test, the general opinion was that the vision that sustained the complexification of Europe had come to a state of complete disarray. Apart from a lack of vision, the attempt to unify different sovereign countries according to some basic economic constituent or contract showed its limits and illusions given the globalizing drive that contain the whole process. A layman's interpretation, however limited in scope, would contend that had the EU passed the referenda test, it would have been to the detriment not only of the various progressive and reactionary groups acting against them but also, and most importantly, it would have been to the detriment of the only superpower left on the world stage. Invariably, a strong EU posits an economic and cultural challenge to the aspirations of world leadership by the US. It is not a matter of "business is business," but as the American dream spells it: the illusions of a way of life, which becomes questionable once alternatives are produced. In these simple terms, and without abandoning a critical position, the cartoon 
controversy offers a different perspective. If, as we have already stated, the media reformist ideology operates by the aura of legitimacy that comes from the governing adjective, then the whole controversy was a tactical ploy to embed the European formulations within a semantic structure that could not fail to alienate the Other (in this case, the Muslim world at large). In so doing, the Other's understanding of Europe ends up shoring up a different vision, one consistent with the notorious American practice of ratfucking[3]. In this case, given the various responses both from the right and the left of the European political spectrum as expressed by the various newspapers and magazines that reproduced the cartoons in the name of freedom of expression, the most striking achievement was to: a) de-contextualize Europe as an independent cultural and political force, and b) to re-align the Western world according to American premises of governance.

One of the most distinctive voices in the European cultural market is the magazine The Economist, characterized by Marx back in the nineteenth century as the blueprint of bourgeoisie capitalist aspirations. The influence of this magazine transcends nationalistic boundaries proper and, as such, its aspiration of serving as a guiding light for the construction of the European project is more than legitimate. Within the various positions that transpire from editorials and signed pieces, one analysis in particular has been in the forefront of the debate: "Culture Wars", which appeared on the 4th of February, 2006. In it, writer Charlemagne refers back to the Salzburg meeting in January 2006 that opened up the discussion to a common European identity:

But European leaders now want to go beyond idealism to assert particular qualities of Europeanness and make specific arguments about the EU. At a recent gathering of the panjandrums of politics and the arts in Salbburg, they did so by making three claims: that there is a distinctive European identity, enshrined in a common European culture; that European culture inspires people in ways that boring things such as markets and trade to not; and that a common European culture should be embodied in common European institutions, that is the EU.[4]

Interestingly, the writer posits the following dilemmas with regards to a common European way of life: a) there is no single European culture, b) any definition that embraces such values as "respect for human rights, the rule of the law, care for the poor and a love of liberty is not distinctively European," c) "Europeans' cultural references are at least as populist and American... as they are high-minded and European," d) the last to try to give Europe a soul, amongst various empires, "were the 
communists of eastern Europe" and, finally e) the problem posited by Turkey's application and that "European distinctiveness can be a way of attacking globalization."

The multicultural space

The five-pronged, or star-shaped hostility - ironically, in respect to the EU's flag symbols - against the notion of a European common identity can be summarized by the last part of Charlemagne's diatribe: "European distinctiveness can be a way of attacking globalization." In other words, any attempt by EU bigwigs to formulate a common cultural platform, one that would be a uniting factor above and beyond the various economic interests, is doomed to failure in the first instance by the present world-system economic construct. Globalization has been attacked, again from the opposite ends of the political spectrum, for being an economic plan to sustain the US's worldview. What Charlemagne fails to acknowledge in his presentation is not only the various contradictions that arises from his position, such as, for example, the invocation that "For too many, it is America that is creative and exciting, not Europe" with reference to building an European mediaculture network, but the unacknowledged fact that constitutes today's European reality. Multicultural societies are under attack around the world for several reasons which can always be reduced to the simplistic polarization of a war of cultures. Thanks to the polarization process aided by media reformist ideology, dominant jingoistic cultural and political positions can recuperate those cultural spaces of negotiation that are created by democratic processes as they become more complex. It is a phenomenon that can be seen to begin, however ironically, with the fall of the Berlin Wall. As the supra-system of the world's political structure began to crumble - the cold détente between the two superpowers - the experimental democratic spaces of active participation that were created, such as lived-multiculturalism, could not continue to function as such. Laboratories of experienced subjective multiplicity were to be brought back under the guidance of a common ideological position. The conflict created ad hoc, thanks to the formulations of disciplined, organic, intellectuals, between geo-cultural spaces within or without specific nation-states, translates into a process of cultural redundancy for the elite social classes. Given that, as Fukuyama testified, history has been vanquished and conquered; the 'new history' could not be but the instantaneous news of the mediatic circle: the consumption of 'star' lives and their lifestyles enclosed within 
the parenthesis of 'reality' programs. An alternate to this summarization is to be found in a very different historical trajectory: the discontinuous process that stems from the Signorie (if we are to talk about, en passant, European frameworks) to ECN (European Counter Network). It would require re-reading Machiavelli through Hardt and Negri's lenses for one, as well as indicating in certain aspects of the French revolution a position that distinctly posited a vision of Europe un-bound by technology. This particularized reading would encompass Rimbaud's presence in 1871 in the Paris Commune, and negotiate formative cultural spaces within the various avant-gardes and twentieth-century movements (Futurism, Dadaism, Surrealism, Lettrism), to finally erupt with May '68 and the end of Movimento '77, only to be resurrected by the electronic agora-heimat of the European-based subcultures present in the World Wide Web.

Still, the EU as a complexification process fails distinctively to redress the multiculturalist project that has been the source of its historical development, even within the European's cultural canon if we expose those cultural agents who saw it as a fundamental principle. Any criticism of the EU project that diverts its scope from addressing this particular issue partakes of the mystifying quality of the media reformist ideology, and in this fashion, collapses the economic trust into the labyrinth of a pseudo-common identity discussion favoring the worldview of a single, universal entity.

\section{NOTES}

[1] Rose, Flemming, "Muhammeds ansigt", Jyllands-Posten, 30-09-2005 as reported in Wikipedia.

[2] "Why I Published Those Cartoons", WashingtonPost, 19/02/2006.

[3] According to Wikipedia: Ratfucking is an American slang term for political sabotage or dirty tricks. It was first brought to public attention by Bob Woodward and Carl Bernstein in their book, All The President's Men (http://en.wikipedia.org/ wiki/Ratfucking, last accessed: 14/06/2006).

[4] The Economist February 4th 2006, p.50. 
